\title{
Effects of Parenting Practices and Marital Satisfaction on Adolescent Behavioral Problems
}

\author{
Dahun Massar* and Prema B. Patil \\ Department of Human Development and Family Studies, College of Community Science, \\ University of Agricultural Sciences, Dharwad, Karnataka, India \\ *Corresponding author
}

\section{A B S T R A C T}

\section{Keywords}

Adolescent, Behavior problems, Parenting practices, Marital satisfaction, Socio-economic status

\section{Article Info}

\section{Accepted:} 05 February 2020 Available Online: 10 March 2020
The present study aimed to know the effect of parenting practices and marital satisfaction on adolescent behavioral problems. The sample comprised of 245 urban and rural adolescents of Dharwad between ages of 12-15 years. The parents of adolescent were also included in the study. The results revealed that adolescents' age and gender (female adolescent) was significantly associated with normal prosocial behavior, internalizing and externalizing problems. Families with less number of children and belonged to high socio-economic status were associated with high prosocial behavior. Specifically, parental positive parenting was significantly associated with adolescents' normal pro social while negative parenting was significantly associated with abnormal externalizing and internalizing behavior problems. Likewise, parents with low marital satisfaction were significantly associated with adolescents' abnormal pro social behavior, externalizing and internalizing behavioral problems. Parental factors accounted for the variance in externalizing problems of rural adolescents $(44.0 \%)$ was found higher compared to urban adolescents $(33.9 \%)$. This signifies that parental factors play as significant risks factors on their adolescent's outcomes and that varies locally.

\section{Introduction}

Adolescence has long been described as a time of emotional turmoil. Adolescents are not constantly in a state of "storm and stress", but emotional highs and lows do increase during early to late adolescence. The transition into adolescence involves a broad range of changes and developmental tasks that may result in increase behavioural problems. Externalizing and internalizing problems are two empirically derived dimensional constructs that have been used frequently to operationalize adolescent behavioral problems (Achenbach and Rescorla, 2001). Externalizing behaviors are evident in children's outward behavior, where the child acts negatively on the surrounding environment and these behaviors consisting of aggressive and delinquent behaviors (like fighting, vandalism, stealing, lying and other 
rule breaking behaviors) Externalizing problems have many consequences some of them are very serious. Early aggression, for example, is associated with frequent fighting in adolescence, convictions by adulthood, peer rejection and failure in school (Tarolla et al., 2002). On the other hand, internalizing behaviors refer to covert behavior problems consisting of anxious and affective symptoms (like worry, sadness, hopelessness, physical symptoms, etc) that are inner- directed and over- controlled that do not disrupt the external environment, they often go unnoticed (Dekovic et al., 2004). The statistics are concerning, given the consequences of internalizing problems in adolescents which include dropping out of school, drug abuse and suicide (McClure \& Pine, 2006). Mental health conditions account for $16 \%$ of the global burden of disease and injury in people aged 10-19 years (WHO, 2018). A community based sample in Bengaluru, revealed the prevalence rates of behavioral problems to be around $12.5 \%$ in children up to 16 years of age (Srinath et al., 2005).

As a result, there has been substantial scholarly interest devoted to identifying risk factors for behavioral problems. Among the most potent risk factors, parenting play as the most influential factor in children's and adolescents' psychosocial adjustment (Fernandez et al., 2012). The concept of parental importance has been well documented since Freud suggested that the infant's emotional tie with the mother provides the foundation for all other later relationships (Ireland and Power, 2004). For more than half a century, research has consistently supported the significance of parenting for child and adolescent psychopathology. As documented in several influential reviews (Georgiou, 2008), warm and accepting parenting styles are consistent predictors of favorable developmental outcomes in children, whereas hostility and rejection predict unfavorable outcomes. Several studies have documented parenting practices as paramount with regard to adolescents' behavioural adjustment: poor supervision/monitoring, harsh discipline (e.g., corporal punishment) and inconsistent discipline (Gershoff, 2002). These three parenting practices accounted as risk factors for adolescent's externalizing behaviors (Lahey \& Waldman, 2008), but there is also growing support for an association with adolescent's internalizing symptoms (Van der Sluis et al., 2015). Recent research has identified marital conflict as a particularly important aspect of marital functioning for adolescent's development outcomes. In the context of marital conflict, has been found to predict adolescent internalizing and externalizing behaviors (Camisasca et al., 2016). Taking into account the previous literature, the aim of the study was to know the effects of positive and negative parenting practices and marital satisfaction on adolescents' behavioral problems.

\section{Materials and Methods}

\section{Research design}

A differential research design was used to compare adolescents' behavior problems, in urban and rural areas of Dharwad, Karnataka. Correlation research method was used to know the strength of relationships between parenting practices and marital satisfaction with adolescents' behavioral problems.

\section{Sample}

The sample of the study comprised of adolescents studying in $7^{\text {th }}, 8^{\text {th }}$ and $9^{\text {th }}$ standards. They were drawn randomly from eight urban and rural government and private schools of Dharwad taluk, Karnataka. The sample was drawn based on these criteria: adolescents belonged to intact family, in the age group of 12 to 15 years and parents are 
literates. A total of 245 respondents participated in the study.

\section{Data collection}

Data collection was collected by using selfadministered questionnaire or scale. For adolescents, a questionnaires i.e., strength and difficulties questionnaire \& Alabama parenting questionnaire (child-form) was distributed individually to assess behavior problems and their perception on parenting practices. While for parents, marital satisfaction questionnaire was distributed through their children to assess marital satisfaction. Out of 360 participated adolescents, only 245 parents returned questionnaires (i.e., 141 urban parents data and 104 are rural parents data) which form the final sample of the study.

\section{Tools}

The following are the questionnaires or tools used for data collection.

\section{Adolescent's behavioral problems}

The Strength and difficulties questionnaire (SDQ) is a brief behavioral scale for 4-17 year olds developed by Goodman (1997). The SDQ was used to study risk symptoms regarding the child's and adolescent's behaviour in the past six months. The scale consists of 25 items rated on 3- point scale ranging from 1 (not true) through 2 (sometimes true) to 3 (certainly true) except items 7, 11, 14, 21 and 25. These items are "reverse-scored". The scale consists of five subscales of five items each. These subscales viz., (i) hyperactivity (ii) emotional Symptoms (iii) conduct problems (iv) Peer problems and the prosocial scale. The two subscales, hyperactivity and conduct problems from the externalizing scale (Cronbach's alpha $=0.84$ ) and the two subscales, emotional symptoms and peer problems form the internalizing scale
(Cronbach's alpha $=0.79$ ). The resultant score ranges from 0 to 20. Higher the scores higher are the behaviors.

\section{Parenting practices}

The Alabama Parenting Questionnaire (Frick, 1991) has been widely used for the purpose of measuring parenting skills in parents of children 6-18 years of age. The APQ consists of 42 items assessing positive and negative parenting practices grouped within six areas: (a) involvement (b) positive parenting (c) poor monitoring/supervision (d) inconsistent discipline (e) use of corporal punishment and (f) use of discipline practices other than corporal punishment. Items are rated on a 5point Likert scale ranging from 1 (never) to 5 (always). No reverse coding is necessary. Two sub-scales of the measure, involvement and positive parenting form the APQ Positive Parenting Scale (Cronbach's alpha $=0.94$ ) while inconsistent discipline, poor monitoring/supervision and use of corporal punishment form the APQ Negative Parenting Scale (Cronbach's alpha $=0.88$ ). The score of each item are added to obtain a total score for each sub-scale that ranges for positive (16-80) and negative parenting (19-95) respectively; higher the scores higher is the parenting practices.

\section{Marital satisfaction}

The Enrich Marital Satisfaction Scale (EMS) developed by Flowers \& Olson (1993) is a scale measuring marital satisfaction of married couples. The EMS scale is a 15 items scale comprising of the ideals distortion (5 items) and marital satisfaction (10 items). It is five point likert scale ranging from 5 'strongly agree' to 1 'strongly disagree'. There is both negative and positive statement. For negative statement reverse scoring will be done. The EMS score of an individual is obtained by revising his or her marital satisfaction score downward based on the idealistic distortion 
score. The total score ranges from 16 to 75 , higher EMS score indicates a higher satisfaction and lower EMS score indicates low marital satisfaction. The reliability test $(\alpha$ $=0.89$ ) of this scale was also observed.

\section{Socio-economic status}

Family socio-economic status was measured using socio-economic status scale developed by Aggarwal et al., (2005). It consists of 23 statements which assess parents' education, occupation, location, number of children, possessions of agricultural land, domestic animals and social status of the family. The scores for each components are added to obtain a total score ranges from very poor $(\leq$ $15)$ to upper high $(\geq 76)$ socio-economic status, the score indicated higher level better is the socio-economic status. The reliability index of this scale was 0.89 .

\section{Data analysis}

Bivariate correlation was employed to know the strength of association between selected independent variables with adolescents' behavior outcomes. Hierarchical regression analysis was used determine the predictive variables of adolescents' behavior outcomes. Three blocks of independent variables (sociodemographics and parental contextual factors) were regressed onto each of the dependent variables (prosocial behavior, externalizing and internalizing problems). Each block contained the independent variables from the previous block and also included new independent variables in order to determine how additional factors influence behavior outcomes. The first block regressed demographic variables (age, gender, number of children and socio-economic status) onto the behaviors outcomes (prosocial, externalizing and internalizing problems). The second block regressed demographic variables plus positive and negative parenting practices onto the behaviors outcomes (prosocial, externalizing and internalizing problems). The third block regressed the demographics, parenting practices and marital satisfaction to analyze the level of contributions onto behaviors outcomes (prosocial, externalizing and internalizing problems).

\section{Results and Discussion}

\section{Percentage distribution of adolescents by behavioral problems}

A perusal of figure 1 shows the percentage distribution of urban adolescents by behavioral problems. Majority $(43.0 \%)$ of adolescents were in borderline level followed by normal $(41.0 \%)$ and abnormal levels (16 $\%)$ of pro social behaviors. For externalizing problems, higher percentages $(48.0 \%)$ of adolescents were in normal level while 36 per cent and 16 percent were in borderline and abnormal levels. For internalizing problems, 52 per cent of adolescents were in normal level, 32 percent and 16 per cent of them were in borderline and abnormal level respectively. The percentage distribution of rural adolescents by behavioral problems is depicted in figure 2. It was observed that majority $(47.0 \%)$ of rural adolescents were in borderline level followed by normal $(31.0 \%)$ and abnormal level (22\%) of pro social behaviors. Regarding externalizing problems, almost equal percentages of adolescents were in normal level $(31 \%)$, borderline $(35 \%)$ and abnormal levels (31. \%). In case of internalizing problems, majority was in borderline (41\%), 40 per cent in normal and 19 percent were in abnormal levels respectively.

\section{Association between selected variables and adolescents behavioral problems}

Table 1 shows the association between independent variables with adolescents' behavior problems. 
Table.1 Bivariate correlation between independent variables with adolescent's behavior problems

\begin{tabular}{|c|c|c|c|c|c|c|}
\hline \multirow[b]{2}{*}{ Independent Variables } & \multicolumn{3}{|c|}{ Urban } & \multicolumn{3}{|c|}{ Rural } \\
\hline & $\begin{array}{c}\text { Pro } \\
\text { social } \\
\text { behavior }\end{array}$ & $\begin{array}{l}\text { Externalizing } \\
\text { problems }\end{array}$ & $\begin{array}{l}\text { Internalizing } \\
\text { problem }\end{array}$ & $\begin{array}{l}\text { Pro } \\
\text { social } \\
\text { behavior }\end{array}$ & $\begin{array}{c}\text { Externalizing } \\
\text { problems }\end{array}$ & $\begin{array}{c}\text { Internalizing } \\
\text { problem }\end{array}$ \\
\hline Age & $0.18^{*}$ & -0.05 & $0.32 * *$ & -0.08 & 0.09 & $0.31 * *$ \\
\hline Gender (female) & $0.19^{*}$ & $-0.27 * *$ & 0.06 & $0.32 * *$ & $-0.43 * *$ & 0.05 \\
\hline Number of children & $0.28 * *$ & $-0.27 * *$ & $-0.33 * *$ & $0.39 * *$ & $-.390 * *$ & $-0.51 * *$ \\
\hline Socio-economic status & $-0.32 * *$ & $0.23 * *$ & $0.31 * *$ & $-0.31 * *$ & $0.40 * *$ & $0.42 * *$ \\
\hline Positive parenting & 0.16 & $-0.26^{* *}$ & $-0.38 * *$ & $0.25^{* *}$ & $-0.37 * *$ & $-0.22 *$ \\
\hline Negative parenting & -0.12 & $0.23 * *$ & $0.34 * *$ & -0.11 & $0.19 *$ & 0.15 \\
\hline Marital satisfaction & -0.37 ** & $0.29 * *$ & $0.30 * *$ & $-0.48^{* *}$ & $0.43 * *$ & $0.41 * *$ \\
\hline
\end{tabular}

**. Correlation is significant at the 0.01 level (2-tailed).

*. Correlation is significant at the 0.05 level (2-tailed).

Table.2 Predictors (Hierarchical regression) of adolescents' behavioral problems

Predictive variables

\begin{tabular}{|c|c|c|}
\hline \multicolumn{3}{|c|}{ Urban } \\
\hline $\begin{array}{c}\text { Pro } \\
\text { social } \\
\text { behavior }\end{array}$ & $\begin{array}{c}\text { Externalizing } \\
\text { problems }\end{array}$ & $\begin{array}{c}\text { Internalizing } \\
\text { problem }\end{array}$ \\
\hline
\end{tabular}

\begin{tabular}{|c|c|c|}
\hline \multicolumn{3}{|c|}{ Rural } \\
\hline $\begin{array}{c}\text { Pro } \\
\text { social } \\
\text { behavior }\end{array}$ & $\begin{array}{c}\text { Externalizing } \\
\text { problems }\end{array}$ & $\begin{array}{c}\text { Internalizing } \\
\text { problem }\end{array}$ \\
\hline
\end{tabular}

\section{Socio-demographics: block 1}

\begin{tabular}{|c|c|c|c|c|c|c|}
\hline Age & -.055 & -.077 & $.333^{* *}$ & -.126 & $-.217^{*}$ & $.267^{* *}$ \\
\hline Gender (female) & $.256^{* *}$ & $-.323^{* *}$ & .112 & $.304 * *$ & $-.399^{* *}$ & $.190^{*}$ \\
\hline Number of children & $.221^{*}$ & $-.277^{* *}$ & $-.245^{* *}$ & $.414 * *$ & $-.298^{*}$ & $-.292^{*}$ \\
\hline Socio-economic status & $.192^{*}$ & .115 & $-.279^{* *}$ & .022 & .180 & .173 \\
\hline Parenting practices: block 2 & \multicolumn{1}{|l}{} & & \\
\hline Positive parenting & 0.044 & -.079 & .088 & .143 & .115 & .150 \\
\hline Negative parenting & -0.077 & $-.233^{*}$ & -.120 & .121 & .033 & .161 \\
\hline Parental relationships: block 3 & & & & & \\
\hline Marital satisfaction & .104 & .121 & .111 & $.322^{* *}$ & .126 & .206 \\
\hline F value & $6.39 * *$ & $6.66 * *$ & $7.67 * *$ & $6.02 * *$ & $7.31 * *$ & $5.23 * *$ \\
\hline R Square & .330 & .339 & .371 & .393 & .440 & .360 \\
\hline
\end{tabular}

Note. $\beta=$ Standardized beta, ${ }^{*} \mathrm{P}<.05$, one tailed, ${ }^{* *} \mathrm{P}<.01$, one tailed 
Figure.1 Percentage distribution of urban adolescents by behavioral problems
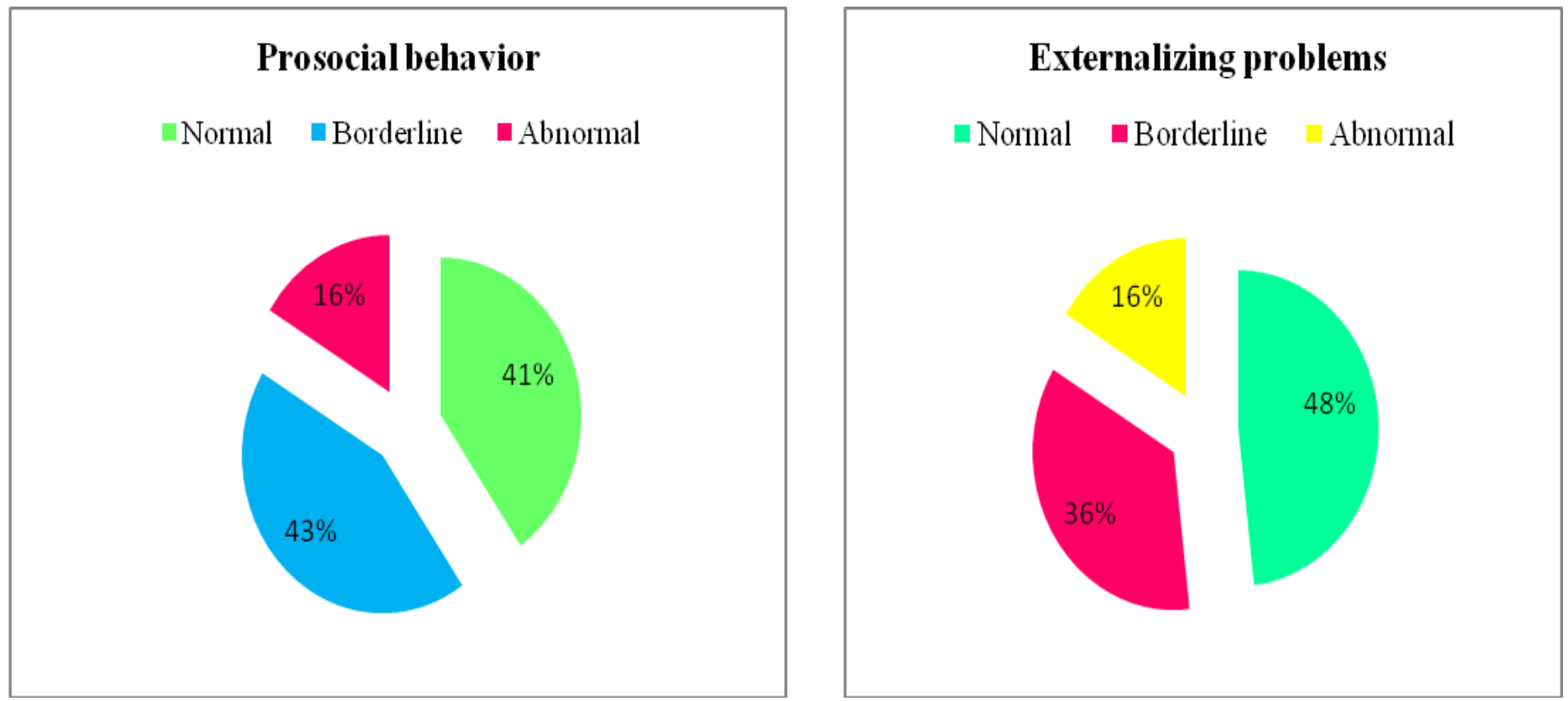

\section{Internalizing problems}

- Normal Borderline Abnormal
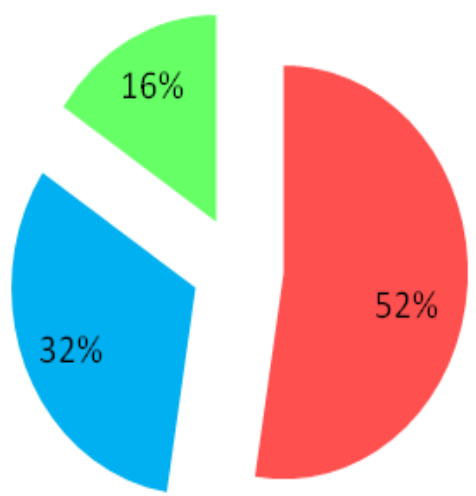
Figure.2 Percentage distribution of rural adolescents by behavioral problems
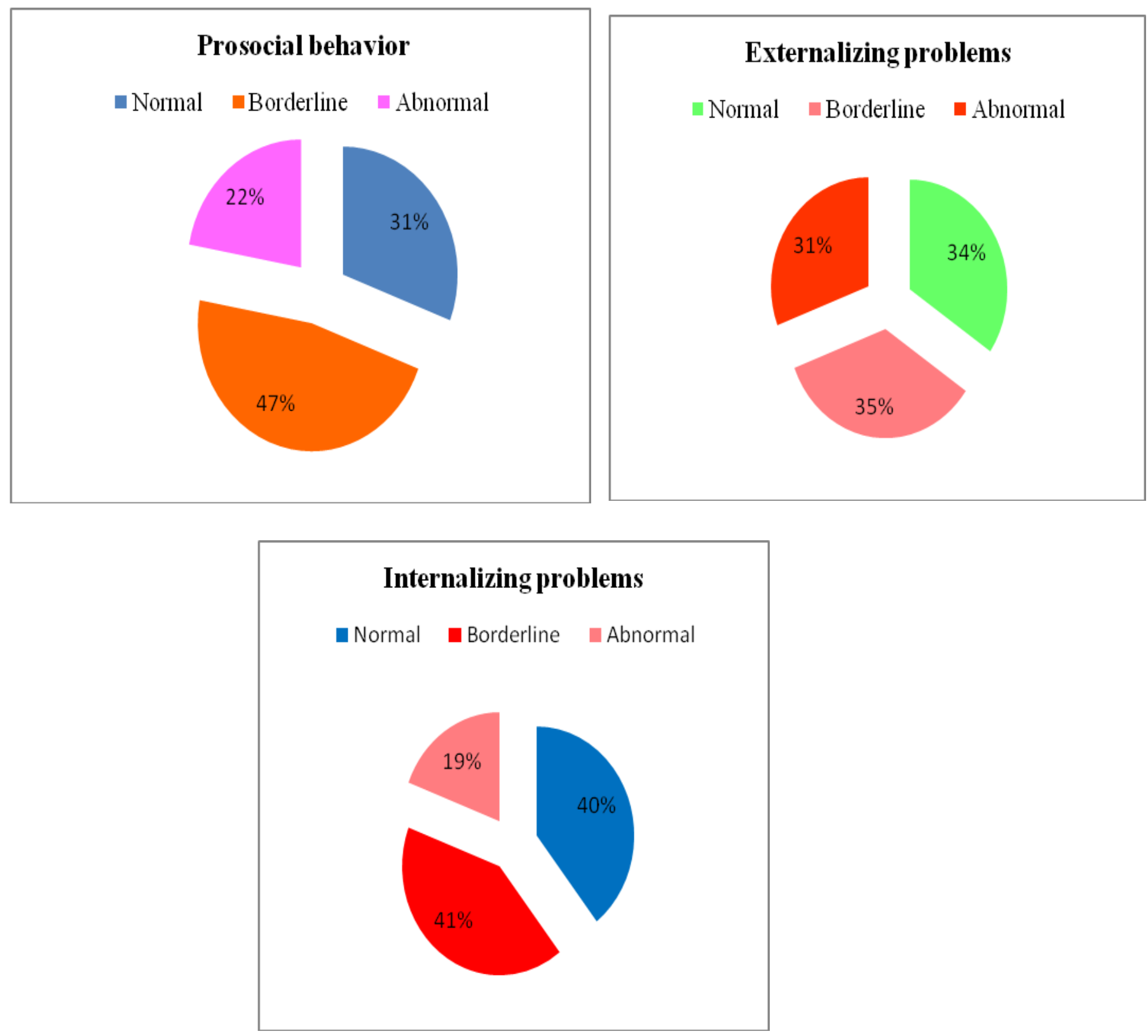

Regarding socio-demographics variables, age was significantly correlated with prosocial behavior $(\mathrm{r}=0.18)$ and internalizing problems $(r=0.32)$ for urban adolescents' while for rural adolescents, age was significantly correlated only with internalizing problems $(\mathrm{r}=0.31)$. Gender of both urban $(\mathrm{r}=0.19,-0.27)$ and rural $(\mathrm{r}=0.32,-0.43)$ adolescents was significantly correlated with pro social behavior and externalizing problems, respectively. Number of children from urban and rural adolescents' families was significantly correlated with prosocial behavior $(\mathrm{r}=0.28,0.39)$, externalizing problems $(\mathrm{r}=-0.27,-0.33)$ and internalizing problems $(\mathrm{r}=-0.39,-0.51)$. Likewise, socio-economic status was 
significantly correlated with prosocial behavior $\quad(\mathrm{r}=-0.32, \quad-0.31)$, externalizing problems $(\mathrm{r}=0.23,0.40)$ and internalizing problems $\quad(r=0.31,0.42)$. For parenting practices irrespective of locality, positive parenting was negatively correlated with externalizing $(\mathrm{r}=-0.26,-0.37)$ and internalizing $(\mathrm{r}=-0.38,-0.22) \quad$ problems while negative parenting was positively correlated with externalizing $(\mathrm{r}=0.23,0.19)$ and internalizing problems. Finally, marital satisfaction was negatively correlated with prosocial behavior $(\mathrm{r}=-0.37,-0.48)$ and positive correlated with externalizing $(\mathrm{r}=0.29,0.43)$ and internalizing $(\mathrm{r}=0.30,0.41)$ problems.

\section{Predictor variables of adolescents' behavioral problems}

Linear regression results (table 2) shows the predictors of adolescents' behavioral problems. For socio-demographics in model 1 , age was significantly associated with internalizing problems $(\beta=.33, p<.01)$ of urban adolescents while for rural adolescents' age was significantly associated with externalizing $(\beta=.21, \mathrm{p}<.05)$ and internalizing $(\beta=.26, p<.01)$ problems. Urban adolescents gender was negatively associated with prosocial behavior $(\beta=-.25, \quad p<.01)$ and externalizing problems $(\beta=.32, \quad \mathrm{p}<.01)$ whereas for rural adolescents' gender, a negative and positive significant association was found with prosocial behavior $(\beta=-.30$, $\mathrm{p}<.01)$, externalizing $(\beta=-.39, \quad \mathrm{p}<.01)$ and internalizing $(\beta=.10, \quad p<.05) \quad$ problems, respectively. Number of children was found as significant contributor for urban and rural adolescents behaviors i.e., prosocial behavior $(\beta=.22, \quad p<.05, \beta=.41, p<01)$, externalizing $(\beta=-.27, \quad p<.05, \quad \beta=-.29, \quad p<01) \quad$ and internalizing $(\beta=-.24, \mathrm{p}<.01, \beta=-.29, \mathrm{p}<05)$ problems. Likewise, socio-economic status was significantly associated with urban adolescents' prosocial behavior $(\beta=.19$, $\mathrm{p}<.05)$ and internalizing $(\beta=-.27, \quad \mathrm{p}<.01)$ problems and non-significant was found for rural adolescents behaviors. Concerning parenting practices, there was non-significant association, except negative parenting revealing as significant contributor to only externalizing problems $(\beta=-.23, \quad p<.05)$ of urban adolescents. For urban adolescents' behaviors, the final model ( $\mathrm{R}$ square) explained $33.0 \%$ of the variance in prosocial behavior, $33.9 \%$ in externalizing and $37.1 \%$ in internalizing problems while for rural adolescents' behaviors, the final model (R square) explained $39.3 \%$ of the variance in prosocial behavior, $44.0 \%$ in externalizing and $36.0 \%$ in internalizing problems.

Although, among both urban and rural adolescents to some extent were found in abnormal level of behavior problems but in comparison rural adolescents had higher percentages of externalizing $(31 \%)$ and internalizing $(19 \%)$ problems and 22 per cent of abnormal pro social behavior (fig. 2). This finding relates the same as was observed by (Breslau et al., 2014) which reported that behavior problems occurred more frequently in children living in deprived rural-urban areas than in children living in urban communities, those adolescents in the deprived neighborhood are at increased risk for externalizing behavior and academic underachievement.

Findings also revealed that age was significantly associated with adolescents' behaviors, reflected that older adolescents (14-15 years-old) had higher pro social behavior and higher internalizing problems than younger adolescents. This implied that externalizing behavior showed a decreasing trend over age in both male and female while prosocial behavior and internalizing problems increase with age. This is in line with the study conducted by Bartels et al., (2011) reported that an increase in problems with increasing age was seen for 
anxiety/depression, while a decrease was observed for somatic complaints, aggressive behavior, social and thought problems. The present study also revealed that gender (female adolescents) was significantly associated with high prosocial behavior, internalizing problems and less of externalizing problems than male adolescents in both urban and rural areas. Likewise, Bartels et al., (2011) reported that female scored higher than male adolescents on internalizing problems and their subscales (anxious/depressed and withdrawn/ depressed), while males score higher than females on externalizing behavior and its subscale rule-breaking. Regarding number of children in the families, there was only few studies relevance to these findings which indicated that families with less number of children was associated with high prosocial behavior and less likely of externalizing and internalizing problems. Rizvi and Najam (2015) supported the findings that smaller family size predicted as significant factors for a lower level of externalizing problems. This perspective reflects the important role of parents in the socio-emotional development of adolescents. It might be that parents from families with less numbers of children used better parenting practices by which they have many more opportunities to invest in their adolescents' well-being. Further, families with high socio-economic status were significantly associated with adolescents' high pro-social behavior and less of internalizing problems. A study by Green et al., (2005) also reported that in Britain, children and youth in the poorest households are up to three times more likely to develop mental health problems than their more advantaged peers. McLaughlin et al., (2011) also confirmed that children and adolescents from families with low SES were up to three times more likely to have mental health problems than their peers from families with a high SES.
Coercive family process model suggests that ineffective parenting is a central component in the development of adolescents' antisocial behaviors. This is in line with the present study which revealed that parental positive parenting was significantly related to adolescents' normal pro social and less of externalizing and internalizing problems. Similarly, Davidson and Cardemil, (2009) were observed that positive involvement contributed to favorable outcomes in Latino families. Additionally, Forgatch and Patterson (2010) revealed that positive involvement occurred when parents showed children love and attention, such as spending time with them and attending to what they say and do. While the ineffective discipline has been linked to Latino youth disruptive behavior and conduct disorder (Gonzales et al., 2012). The study also found that higher the negative parenting lower was adolescents' pro social behavior and higher externalizing and internalizing problems. These findings explained a possible mechanism through negative parenting behaviors which may lead adolescents to invest more time and attention in their peer relationships and may make adolescents more susceptible to the influence of peers (Svensson, 2003), which consequently, may lead to more participation in delinquent or aggressive behaviors. Several longitudinal studies have supported this transactional model and found that negative parenting behaviors, such as permissiveness, inconsistent discipline or punishment (corporal) or a lack of parental involvement predicted increase in externalizing and internalizing symptoms (Hawes et al., 2011).

Many studies have demonstrated that child problems are most likely to occur when marital conflict is intense, openly hostile and child-related. A similar finding in the present study was observed wherein parents' marital dissatisfaction was significantly associated with adolescents' abnormal pro social 
behavior, externalizing and internalizing behavioral problems. Further, a higher level of familial conflicts resulted in a higher level of internalizing problems (depressive symptoms, emotional detachment from others, etc.) among adolescents (Bamaca et al., 2012).

Findings by Buehler and Gerard (2002) also confirmed that marital conflict was associated with greater use of harsh discipline by parents, with reduced levels of parental involvement and with more frequent parentadolescent conflict. These, in turn, were associated with greater levels of maladjustment in children and adolescents.

Conclusion and implication of the study are as follows:

Confirming prior research which was observed by Davidson and Cardemil, (2009) that positive parenting contributed to the favorable outcomes in Latino families. While the ineffective discipline has been linked to Latino youth disruptive behavior and conduct disorder (Gonzales et al., 2012).

The study also highlighted that parenting practices was associated with adolescents' behavior problems. Comparably, marital satisfaction was also found significantly associated with adolescents' behaviors problems. Mental health service providers and the research scholars who wish to prevent adolescents externalizing and internalizing problems should consider family oriented programs that facilitate better parent- child communication, parental relationships and parents' psychological well being. Interest scholars or prevention specialist can think of taking up effective program such as Systematic Training for Effective Parenting (STEP) on parenting practices for increasing maternal and paternal knowledge on parenting, decreasing parental negative perceptions of the target child's behavior.

\section{Acknowledgments}

The authors would like to acknowledge Dr. Prema B. Patil, Assistant professor (Home Science) as the supervisor. This study is a part of $\mathrm{PhD}$ research work and was financially supported under the scheme "National Fellowship and Scholarship for Higher Education of ST Students" to pursue M.Phil./Ph.D. Degree.

\section{References}

Achenbach, T. M. and Rescorla, L. A., 2001, Manual for the ASEBA school age forms and profiles. Burlington, VT: University of Vermont, Research Center for Children, Youth \& Families.

Aggarwal, O.P., Bhasin, S. K., Sharma, A.K., Chhabra, P., Aggarwal, K. and Rajoura, O.P., 2005, A new instrument (scale) for measuring the socioeconomic status of a family: Preliminary study, Indian J. Community Medicine, 30(4):111-114.

Bámaca-Colbert, M. Y., Umaña-Taylor, A. J. and Gayles, J. G., 2012, A developmental-contextual model of depressive symptoms in Mexican-origin female adolescents. Developmental Psychology, 48(2): 406-421.

Bartels, M., van de Aa, N., van Beijsterveldt, C. E., Middeldorp, C. M. and Boomsma, D. I., 2011, Adolescent selfreport of emotional and behavioral problems: interactions of genetic factors with sex and age. J. Canadian Academy of Child and Adolescent Psychiatry, 20(1): 35-52.

Breslau, J., Marshall, G. N., Pincus, H. A. and Brown, R. A., 2014, Are mental disorders more common in urban than rural areas of the united states? $J$. Psychiatric Research, 56: 50-55.

Buehler, C. and Gerard, J. M., 2002, Marital conflict, ineffective parenting, and children's and adolescents' maladjustment. $J$. Marriage and 
Family, 64(1): 78-92.

Camisasca, E., Miragoli, S. and Di Blasio, P., 2016, Families with distinct levels of marital conflict and child adjustment: Which role for maternal and paternal stress?. J. Child and Family Studies, 25(3): 733-745.

Davidson, T. M. and Cardemil, E. V., 2009, Parent-child communication and parental involvement in Latino adolescents. $\quad J . \quad$ Early Adolescence, 29(1): 99-121.

Deković, M., Buist, K. and Reitz, E., 2004, Stability and changes in problem behavior during adolescence: Latent growth analysis. J. Youth and Adolescence, 33(1): 1-12.

Fernandez, Rodríguez-A., Droguet, L. and Revuelta, L., 2012, School and personal adjustment in adolescence: The role of academic self-concept and perceived social support. J. Psychodicatics, 17: 397-414.

Flowers, B.J. and Olson, D.H., 1993, Enrich marital satisfaction scale: A brief res. and clinical tool, J. Family Psychology, 7(2):176-185.

Forgatch, M. S. and Patterson, G. R., 2010, Parent management training-Oregon Model An intervention for anti-social behaviors on children and adolescent. Evidence-Based Psychotherapies For Children And Adolescents ( $2^{\text {nd }}$ Edi.). New York, Guildford press. pp.159172.

Frick, P. J., 1991, The Alabama parenting questionnaire. Unpublished rating scale, University of Alabama.

Gershoff, E. T., 2002, Corporal punishment by parents and associated child behaviors and experiences: a metaanalytic and theoretical review. Psychological bulletin, 128(4): 539-579.

Georgiou, S. N., 2008, Bullying and victimization at school: The role of mothers. British J. Educational Psychology, 78: 109-125.

Gonzales, N. A., Germán, M. and Fabrett, F. C., 2012, US Latino youth. In Handbook of race and development in mental health, Springer, New York, pp. 259-278.

Goodman, R., 1997, The strengths and difficulties questionnaire: A research note. J. Child Psychology and Psychiatry, 38: 581-586.

Hawes, D. J., Dadds, M. R., Frost, A. D. and Hasking, P. A., 2011, Do childhood callous-unemotional traits drive change in parenting practices?. J. Clinical Child and Adolescent Psychology, 40(4): 507518.

Ireland, J. L. and Power, C. L., 2004, Attachment, emotional loneliness, and bullying behavior: A study of adult and young offenders. Aggressive Behavior. 30: 298-312.

Lahey, B. B. and Waldman, I. D., 2008, Oppositional defiant disorder, conduct disorder, and juvenile delinquency. Child and adolescent psychopathology, 335-369.

Lovibond, P. F and Lovibond S. H., 1995, The structure of negative emotional states: comparison of the depression anxiety stress scales (DASS) with the beck depression and anxiety inventories. Behaviors Res. Therapy, 33(3):335-343.

McLaughlin, K. A., Breslau, J., Green, J. G., Lakoma, M. D., Sampson, N. A. and Zaslavsky, A. M., 2011, Childhood socio-economic status and the onset, persistence, and severity of Diagnostic and Statistical Manual (DSM-IV) mental disorders in a US national sample. Social Science and Medicine, 73(7): 1088-1096.

McClure, E. B. and Pine, D.S., 2006, Social anxiety and emotion regulation: A model for developmental 
psychopathology perspectives on anxiety disorders. In D. Cicchetti \& D. J. Cohen (Eds.), Developmental psychopathology: Risk, disorder, and adaptation Hoboken, NJ: John Wiley \& Sons, 2nd ed., Vol. 3: pp. 470-502.

Rapport, M. D., Denney, C. B., Chung, K. M. and Hustace, K., 2001, Internalizing behavior problems and scholastic achievement in children: Cognitive and behavioral pathways as mediators of outcome. J. Clinical Child Psychology, 30(4): 536-551.

Rizvi, S. F. I. and Najam, N., 2015, Emotional and behavioral problems associated with parenting styles in Pakistani adolescents. Transactions on Education and Social Sciences, 8(2):613.

Svensson, R., 2003, Gender differences in adolescent drug use: The impact of parental monitoring and peer deviance. Youth and Society, 34(3): 300-329.
Srinath, S., Girimaji, S. C., Gururaj, G., Seshadri, S., Subbakrishna, D. K., Bhola, P. and Kumar, N., 2005, Epidemiological study of child and adolescent psychiatric disorders in urban \& rural areas of Bangalore, India. Indian $\quad J . \quad$ Medical Research, 122(1): 67-79.

Tarolla, S., Wagner, E., Rabinowitz, J. and Tubman, J., 2002, Understanding and treating juvenile offenders: A review of current knowledge and future directions. Aggression and Violent Behavior, 7(2): 125-144.

Van der Sluis, C. M., van Steensel, F. J. and Bögels, S. M., 2015, Parenting and children's internalizing symptoms: How important are parents? J. Child and Family Studies, 24(12): 3652-3661.

WHO, 2018: Key facts: Adolescent Mental Health. https://www.who.int/newsroom/fact-sheets/detail/adolescentmental-health.

\section{How to cite this article:}

Dahun Massar and Prema B. Patil. 2020. Effects of Parenting Practices and Marital Satisfaction on Adolescent Behavioral Problems. Int.J.Curr.Microbiol.App.Sci. 9(03): 109-120. doi: https://doi.org/10.20546/ijcmas.2020.903.014 